\title{
Choosing the best method for radiological assessment of patellofemoral osteoarthritis
}

\author{
F M Cicuttini, J Baker, D J Hart, T D Spector
}

\begin{abstract}
Objective-To assess the reproducibility of different methods of radiological assessment of patellofemoral osteoarthritis (OA) and to determine which is the best view as a research tool in epidemiological studies of knee $O A$ requiring explicit diagnostic criteria to classify the disease in the general population.
\end{abstract}

Methods-A population based study of 252 unrelated, normal individuals (504 knees) was performed. Lateral and skyline radiographs from each individual were graded for joint space narrowing and osteophytes using a standard atlas. Reproducibility was assessed by two observers on 50 knees. Radiographic features were assessed on their ability to predict knee pain.

Results-The skyline views performed better than the lateral views in the assessment of patellofemoral joint OA. The reproducibility for osteophytes was high $(\kappa>0.8)$ and that for joint space narrowing moderate $(\kappa>0.6)$ for both lateral and skyline views. Although the specificity for detecting knee pain was similar in both views, the sensitivity of skyline views in the assessment of knee pain was greater $(52 \cdot 8 \%$ versus $30 \%)$. The odds ratio for skyline osteophytes as a predictor of knee pain was $7.66(95 \%$ confidence interval (CI) 3.68 to 15.90 ); that for osteophytes seen on lateral view was 1.83 (95\% CI 0.96 to 3.49$)$. Narrowing on both views was a poor predictor of pain. There was frequent disagreement between the lateral and skyline views for detecting osteophytes.

Conclusion-In a community based study, skyline views performed better than lateral views in terms of reproducibility and for identifying symptomatic patellofemoral joint OA. Skyline radiographs should be the preferred method for examining the patellofemoral joint in such studies.

(Ann Rheum Dis 1996; 55: 134-136)

Osteoarthritis (OA) is a major health problem in developed countries. For subjects over the age of 45 years, most population surveys show that the presence of radiographically determined OA of the knee varies between 14 and $30 \%$, and increases steadily with age. ${ }^{1}$ Most studies suggest that the proportion of radiological disease that is symptomatic is between 40 and $80 \% .^{2}$ This has led to the suggestion that clinical and radiological OA are different entities, or that the techniques used routinely to quantify radiographic changes are inadequate.

It has been shown that symptomatic knee OA may often be related to patellofemoral disease that is not revealed by conventional anteroposterior radiographs and is difficult to grade reproducibly. ${ }^{3-5}$ Although one small clinical study has shown the skyline view to give better results than the lateral view, ${ }^{6}$ the optimal method for assessing this joint site radiologically requires confirmation, particularly for use in population based surveys. This is important in understanding the epidemiology and natural history of knee OA. The aim of this study was to determine the optimal method for assessing patellofemoral $\mathrm{OA}$ in a population based survey.

\section{Methods}

SELECTION OF CASES

This was a population based study of 252 unrelated, middle aged women who were randomly selected from a group of 504 as part of a twin study of OA. The participation rate in the twin study was $83 \%$. Only one twin of each twin pair was randomly included. Compared with another population based sample of middle aged women described previously, ${ }^{7}$ this group did not differ in prevalence of $\mathrm{OA}$ or risk factors for OA. The analyses performed in this report refer to the (504) knee joints, examined as separate units.

Each subject was interviewed with a standard questionnaire for arthritis and joint symptoms, and the joints were examined in a systematic way using previously validated and reproducible techniques. ${ }^{7}$ The following radiographic views of the patellofemoral joint were obtained: a standing lateral (mediolateral) view in $30^{\circ}$ flexion; a skyline (inferosuperior) view in $45^{\circ}$ flexion using a Perspex positioning wedge with the subject supine. Lateral radiographs were available on all knees $(n=504)$ from the onset of the study, but skyline radiographs were also available on an unselected sample of 356 collected after the initial nine months of the study.

INTRAOBSERVER AND INTEROBSERVER REPRODUCIBILITY

All radiographs were independently assessed by two trained observers using an atlas. The 
Table 1 Intraobserver and interobserver $\mathrm{\kappa}$ coefficients (95\% confidence intervals) for level of agreement for lateral and skyline views of the patellofemoral joint

\begin{tabular}{|c|c|c|c|c|}
\hline \multirow{2}{*}{$\begin{array}{l}\text { Radiographic } \\
\text { feature of } O A\end{array}$} & \multicolumn{2}{|c|}{ Dichotomised at the level of grade 1 change } & \multicolumn{2}{|c|}{ Using radiographic grades $(0-3)$} \\
\hline & Lateral view & Skyline view & Lateral view & Skyline view \\
\hline \multicolumn{5}{|l|}{ Intraobserver } \\
\hline $\begin{array}{l}\text { Joint space narrowing } \\
\text { Osteophyte }\end{array}$ & $0.60(0.52$ to 0.68$)$ & $0.80(0.72$ to 0.88$)$ & $0.58(0.52$ to 0.64$)$ & $0.84(0.79$ to 0.89$)$ \\
\hline Usteophyte & $0.84(0.79$ to 0.89$)$ & $0.90(0.83$ to 0.97$)$ & $0.88(0.84$ to 0.92$)$ & $0.92(0.87$ to 0.97$)$ \\
\hline \multicolumn{5}{|l|}{ Interobserver } \\
\hline Joint space narrowing & $0.60(0.52$ to 0.68$)$ & $0.80(0.74$ to 0.86$)$ & $0.62(0.55$ to 0.69$)$ & $0.84(0.76$ to 0.92$)$ \\
\hline Osteophyte & $0.80(0.75$ to 0.85$)$ & $0.90(0.84$ to 0.96$)$ & $0.84(0.76$ to 0.92$)$ & $0.88(0.82$ to 0.94$)$ \\
\hline
\end{tabular}

observers were blind to the clinical findings. The radiological features of $O A$ in the patellofemoral joint were graded on a four point scale $(0-3)$ for individual features of osteophytes and joint space, using a published atlas of individual features. ${ }^{8}$

The intraobserver and interobserver variability were assessed by the two observers independently grading 50 sets of lateral and skyline knee films selected to include the full range of radiological features. This was done on two occasions one week apart and without knowledge of the previous assessment using the atlas. ${ }^{8}$ Each film was read blind and independently of other views from the same subject. The two sets of results from each observer were compared for intraobserver variability and the results of the two observers were then compared for interobserver variability.

In subsequent analyses, the initial scoring results of the two observers were compared and, in the case of disagreement, the radiographs were reviewed by the two observers together with a third independent

Table 2 Sensitivity, specificity, and positive predictive value of radiological abnormalities of the lateral and skyline patellofemoral views for determining the presence of knee pain

\begin{tabular}{|c|c|c|c|}
\hline & $\begin{array}{l}\text { Sensitivity } \\
(\%)\end{array}$ & $\begin{array}{l}\text { Specificity } \\
(\%)\end{array}$ & $\begin{array}{l}\text { Positive } \\
\text { predictive value } \\
(\%)(95 \% \text { CI) }\end{array}$ \\
\hline $\begin{array}{l}\text { Osteophytes + narrowing } \\
\text { AP view } \\
\text { Lateral view } \\
\text { Skyline view }\end{array}$ & $\begin{array}{l}33 \\
30 \\
52 \cdot 8\end{array}$ & $\begin{array}{l}85 \cdot 8 \\
79 \cdot 8 \\
83 \cdot 8\end{array}$ & $\begin{array}{l}22 \cdot 0(18 \cdot 2 \text { to } 25 \cdot 8) \\
15 \cdot 5(11 \cdot 2 \text { to } 19 \cdot 8) \\
26(20 \cdot 2 \text { to } 31 \cdot 8)\end{array}$ \\
\hline $\begin{array}{l}\text { Osteophytes } \\
\text { AP view } \\
\text { Lateral view } \\
\text { Skyline view }\end{array}$ & $\begin{array}{l}40 \cdot 7 \\
27 \cdot 8 \\
52 \cdot 8\end{array}$ & $\begin{array}{l}88 \cdot 7 \\
82 \cdot 9 \\
87 \cdot 3\end{array}$ & $\begin{array}{l}30 \cdot 1(24 \cdot 4 \text { to } 35 \cdot 8) \\
16 \cdot 1(12 \cdot 5 \text { to } 19 \cdot 7) \\
38 \cdot 0(32 \cdot 4 \text { to } 43 \cdot 6)\end{array}$ \\
\hline $\begin{array}{l}\text { Narrowing } \\
\text { AP view } \\
\text { Lateral view } \\
\text { Skyline view }\end{array}$ & $\begin{array}{l}13 \cdot 3 \\
11 \cdot 1 \\
10 \cdot 9\end{array}$ & $\begin{array}{l}93 \cdot 4 \\
91 \cdot 2 \\
87 \cdot 6\end{array}$ & $\begin{array}{l}11.8(7.4 \text { to } 16.2) \\
13.0(6.5 \text { to } 19.5) \\
12.5(7.4 \text { to } 17.6)\end{array}$ \\
\hline
\end{tabular}

$\mathrm{AP}=$ Anteroposterior

Table 3 Odds ratios of knee pain in those with radiological abnormalities versus no radiological abnormality on lateral and skyline patellofemoral views

\begin{tabular}{|c|c|c|c|}
\hline & Pain & $\begin{array}{l}\text { Prevalence } \\
(\text { No }(\%))\end{array}$ & $\begin{array}{l}\text { Odds ratio } \\
(95 \% \text { CI })\end{array}$ \\
\hline \multicolumn{4}{|c|}{ Osteophytes + narrowing } \\
\hline Lateral view & \multirow{2}{*}{$\begin{array}{l}\text { Yes }(n=54) \\
\text { No }(n=450) \\
\text { Yes }(n=36) \\
\text { No }(n=322)\end{array}$} & \multirow{2}{*}{$\begin{array}{l}16(29 \cdot 6) \\
93(20 \cdot 7) \\
19(52 \cdot 8) \\
54(16 \cdot 8)\end{array}$} & $1.62(0.86$ to 3.03$)$ \\
\hline Skyline view & & & $5.57(2.72$ to 11.40$)$ \\
\hline \multicolumn{4}{|l|}{ Osteophytes } \\
\hline Lateral view & \multirow{2}{*}{$\begin{array}{l}\text { Yes }(n=54) \\
\text { No }(n=450) \\
\text { Yes }(n=36) \\
\text { No }(n=322)\end{array}$} & \multirow{2}{*}{$\begin{array}{l}15(27 \cdot 8) \\
78(17 \cdot 2) \\
19(52 \cdot 8) \\
41(12 \cdot 7)\end{array}$} & $1.83(0.96$ to 3.49$)$ \\
\hline Skyline view & & & 7.66 (3.68 to 15.90$)$ \\
\hline \multicolumn{4}{|l|}{ Narrowing } \\
\hline Lateral view & \multirow{2}{*}{$\begin{array}{l}\text { Yes }(n=54) \\
\text { No }(n=450) \\
\text { Yes }(n=36) \\
\text { No }(n=282)\end{array}$} & \multirow{2}{*}{$\begin{aligned} 6 & (11 \cdot 1) \\
40 & (8 \cdot 9) \\
5 & (13 \cdot 9) \\
35 & (10 \cdot 9)\end{aligned}$} & $1.28(0.52$ to 3.18$)$ \\
\hline Skyline view & & & $1.32(0.48$ to 3.62$)$ \\
\hline
\end{tabular}

observer. Pain was defined as the patient ever having a previous episode of pain in the knee lasting for more than 15 days.

STATISTICAL ANALYSIS

Kappa ( $\kappa$ ) coefficients were calculated to assess reproducibility. The association between radiological severity of $\mathrm{OA}$ and knee pain was examined by $\chi^{2}$ for trend. Odds ratios and $95 \%$ confidence intervals were calculated for those with pain and radiological features of $O A$ versus those with pain and no radiological features. Logistic regression software (SPSS for Windows) was used to adjust for confounders.

\section{Results}

INTRAOBSERVER AND INTEROBSERVER

REPRODUCIBILITY

The intraobserver and interobserver assessment of osteophytes at the patellofemoral joint on lateral and skyline views had good reproducibility both when the full grading system was used and when the disease feature was dichotomised at the level of grade 1 change $(\kappa>0.8)$ (table 1). However, the skyline view performed more reproducibly than the lateral view both within observer and between observers in the assessment of joint space narrowing $(0 \cdot 8$ versus $0 \cdot 6)$.

\section{COMPARISON OF LATERAL VERSUS SKYLINE} VIEWS IN ASSESSING PATELLOFEMORAL JOINT DISEASE

Radiographs obtained in the two views provided results that were in agreement for presence of disease in 30 of 356 knees with respect to osteophytes and in 22 of 356 knees in respect of narrowing, but that were discordant in 56 and 30 knees, respectively. The skyline score was derived from the worst category for either of the facets. There was good agreement between the maximum joint space narrowing observed on the skyline view and that obtained with the lateral view $(\kappa=0.55)$, and moderate agreement for the presence of osteophytes in the two patellofemoral views $(\kappa=0.42)$.

SENSITIVITY, SPECIFICITY, AND POSITIVE PREDICTIVE VALUE OF RADIOLOGICAL KNEE OA FOR PREDICTING KNEE PAIN

As there is no gold standard for defining OA, we examined the sensitivity, specificity, and predictive value of positive radiological 
abnormality (osteophytes, narrowing, or both) in the lateral and skyline views for predicting pain in that knee (table 2). The sensitivity of radiological abnormalities on the lateral view and skyline view for predicting knee pain was $30 \%$ and $52 \cdot 8 \%$, respectively, with a specificity of $79 \cdot 6 \%$ and $83.3 \%$. Skyline osteophytes were the best predictors of pain (38\%).

An alternative means of examining this association was to calculate the odds of having knee pain for those with radiological abnormalities, compared with those without radiological abnormalities, on the lateral and skyline patellofemoral joint views (table 3). The crude odds ratios are presented in the text and tables. Logistic regression was used to adjust for age and body mass index, but no significant differences were noted compared with the crude results. The association between knee pain and radiological changes was strongest for the skyline view, with odds ratio $5.57(95 \%$ CI 2.72 to 11.4$)$ for osteophytes, narrowing, or both, on skyline radiographs and odds ratio $7.66(95 \%$ CI 3.68 to $15 \cdot 9$ ) for osteophytes alone. The association between radiological severity (for osteophytosis and joint space narrowing) and pain was examined by a $\chi^{2}$ test for trend. There was a significant association between the grade of skyline osteophytes and pain $\left(\chi^{2}\right.$ statistic for trend $=40.30,1 \mathrm{df}, \mathrm{p}<0.001$ ), but not between lateral view osteophytes and pain $\left(\chi^{2}\right.$ statistic for trend $=1 \cdot 34,1 \mathrm{df}, p=0.25)$. No significant trend was observed between pain and narrowing on either skyline view $\left(\chi^{2}\right.$ statistic for trend $=0.51,1 \mathrm{df}, \mathrm{p}=0.50$ ) or lateral patellofemoral view $\left(\chi^{2}\right.$ statistic for trend $=1 \cdot 98,1 \mathrm{df}, \mathrm{p}=0 \cdot 16$ ).

\section{Discussion}

Epidemiological studies of knee OA require explicit diagnostic criteria to classify the disease in the general population. In assessing the optimal method for determining patellofemoral OA, we found that the skyline views performed better than the lateral views: though reproducibility of both views for detecting osteophytes was high, skyline views performed much better than lateral views, both within and between observers, for detecting joint space narrowing. These findings in a population based study are in agreement with those of a recent, small hospital outpatient study. ${ }^{6}$ In the present study, the reproducibility of skyline views and standard lateral views was also compared in 50 patients attending a rheumatology outpatient department with OA of the knee; the skyline view performed more reproducibly than the lateral radiograph for all joint features.

In the present study, as in a previous one, ${ }^{9}$ the presence of osteophytes was the best predictor of pain in that knee joint. Furthermore, there was a strong association between the radiographic severity of skyline view osteophytes, but not lateral view osteophytes. Although the specificity for detecting knee pain was similar in lateral and skyline views, the sensitivity of skyline views in the assessment of knee pain was greater than that of lateral views. Narrowing on both views was a poor predictor of pain.

In summary, these data from a population based study confirm that the skyline view should be the preferred method of assessing the patellofemoral joint in radiological surveys of osteoarthritis of the knee, but that lateral views may nevertheless provide some additional information on the patellofemoral compartment.

This study was partially funded by a Project Grant from the Arthritis and Rheumatism Council. We are grateful to the staff of the Radiology Department at St Thomas' Hospital, the volunteers, and the twin research team.

1 Bagge E, Bjelle A, Eden S, Svanborg A. Osteoarthritis in the elderly. Ann Rheum Dis 1991; 50: 535-9.

2 Davis M A, Ettinger W H, Neuhaus J M, Mallon K P. Knee $O A$ and physical functioning: evidence from the NHANES epidemiology follow-up study. $f$ Rheumatol 1991; 18: 591-8.

3 Cooper C, Cushnaghan J, Kirwan J, et al. Radiologica assessment of the knee joint in osteoarthritis. $\mathrm{Br} f$ Rheumatol 1992; 51: 80-2.

4 McAlindon T E, Snow S, Cooper C, Dieppe P A Radiographic patterns of knee osteoarthritis in the community: the importance of the patellofemoral joint. Ann Rheum Dis 1993; 51: 844-9.

5 Ledingham J, Regan M, Jones A, Doherty M. Radiographic patterns and associations of osteoarthritis of the knee in patients referred to hospital. Ann Rheum Dis 1993; 52: patients

6 Jones A C, Ledingham J, McAlindon T, et al. Radiographic assessment of patellofemoral osteoarthritis. Ann Rheum Dis 1993; 52: 655-8.

7 Hart D J, Spector T D. Cigarette smoking and risk of osteoarthritis in the general population: the Chingford Study. Ann Rheum Dis 1993; 52: 93-6.

8 Burnett S, Hart D J, Cooper C, Spector T D. A radiographic atlas of osteoarthritis. London: Springer-Verlag, 1994.

9 Spector T D, Hart D J, Harris P A, Dacre J E. A definition of osteoarthritis of the knee for epidemiological studies. Ann Rheum Dis 1993; 52: 790-4. 